\title{
Cold winter temperatures condition the egg-hatching dynamics of a grape disease vector
}

\author{
Julien Chuche • Denis Thiéry
}

Received: 20 October 2008 /Revised: 10 April 2009/Accepted: 10 April 2009/Published online: 29 April 2009

(C) The Author(s) 2009. This article is published with open access at Springerlink.com

\begin{abstract}
The leafhopper Scaphoideus titanus is the vector of a major phytoplasma grapevine disease, Flavescence dorée. The vector's distribution is in Eastern and Northern Europe, and its population dynamics varies as a function of vineyard latitude. We tested the hypothesis that hatching dynamics are cued by cold temperatures observed in winter. We exposed eggs from a natural population to simulated "cold" and "mild" winters and varied the exposure time at $5{ }^{\circ} \mathrm{C}$ from 0 to 63 days. We show that temperature cooling mainly affected the onset of hatching and is negatively correlated to the cold time exposure. The majority of hatchings occurred more quickly in cold rather than in mild winter simulated conditions, but there was no significant difference between the duration of hatching of eggs whatever the cold time exposure. In agreement with the Northern American origin of the vector, the diapause termination and thus the timing regulation of egg hatching require cold winters.
\end{abstract}

Keywords Diapause · Flavescence dorée - Leafhoppers · Risk-spreading strategies · Invasive species $\cdot$ Scaphoideus titanus

\section{Introduction}

Growing international trade may increase the incidence of alien species and could lead to crop injuries and important environmental and/or economic problems (Pimentel et al.

J. Chuche $\cdot$ D. Thiéry $(\square)$

UMR INRA 1065 en Santé Végétale, INRA, BP 81,

Institut Supérieur de la Vigne et du Vin, IFR 103,

33883 Villenave d'Ornon Cedex, France

e-mail: thiery@bordeaux.inra.fr
2005; Meyerson and Mooney 2007). A major factor for geographical extension or shift of nonindigenous species is the occurrence and availability of suitable food resources. When food is not available throughout the year, the synchrony of larval stages with food availability is often the critical step for phytophagous insects (Van Asch and Visser 2007). For many species living in temperate environments, one way to escape an adverse season like winter is entering diapause (Tauber and Tauber 1976). Fitness is thus often conditioned to this survival strategy (Kroon and Veenendaal 1998; Ellers and van Alphen 2002; Wang et al. 2006), which is a key factor for synchrony with food resources. Larvae that emerge when food availability is not optimal for their development must disperse to more suitable habitats and will thus often pay fitness costs (Van Asch and Visser 2007). On the contrary, those emerging from diapause when the host plant is suitable for their development should increase their fitness (Dixon 1976; Watt and McFarlane 1991; Yukawa 2000). Diapause is genetically controlled and regulated by environmental factors such as photoperiod and temperature (Tauber and Tauber 1976; Denlinger 2002). However, diapause entry or termination is subjected to polymorphism, which is supposed to allow risk-spreading strategies (Menu and Desouhant 2002). The effect of chilling on the end of diapause and its consequences on insect emergence is well known in orders as diverse as Orthoptera (Higaki and Ando 2002), Diptera (Collier and Finch 1983), or Lepidoptera (Wipking 1995). Better understanding of this species' life history traits and behavior will aid our understanding of its geographical range, and this in turn will improve one's ability to forecast the occurrence of this disease. However, if environmental conditions are major factors in the establishment and the spread of an exotic species and act to determine its invasive potential, biotic (e.g., food, predation, parasitism) and abiotic 
(e.g., climate, altitude) factors are always linked, and it may be difficult to determine the influence of each individual component.

The leafhopper Scaphoideus titanus (Homoptera: Cicadellidae) is a harmful vector of a phytoplasma disease of grape, the Flavescence dorée, and in that respect is one of the current major threats in European viticulture. It originates from North America, in the Great Lakes region (Vidano 1966), and was accidentally introduced in Europe during the 1950s (Bonfils and Schvester 1960). This species is considered monophagous, though it may feed on few plants not belonging to Vitaceae in laboratory as Cineraria maritima (Syn. Senecio cineraria; Asteracea), Vicia faba (Fabaceae; Caudwell et al. 1970) and in nature on Ulmus americana (Ulmaceae; Gibson 1973). In France, females oviposit on grapevine (Vitis vinifera) woody canes from summer ending to autumn, eggs enter diapause, and then larvae hatch from May to July of the following year (Boudon-Padieu 2000a). The ecology of this insect is still poorly understood, even if few recent studies document phytoplasma transmission (Bressan et al. 2005a; 2006), spatial distribution (Bosco et al. 1997; Lessio and Alma 2006), fitness variation (Bressan et al. 2005b), or population genetics (Papura et al. 2006, 2007; Bertin et al. 2007).

As $S$. titanus is a recently introduced monophagous species whose host occurs from ca. 35 to $50^{\circ} \mathrm{N}$ and which suffers little predation or parasitism in Europe, its main biotic factors are constant. However, the leafhopper does not occur in all the vineyards, and so far, only climatic factors can explain this (Fig. 1). In fact, S. titanus is found in vineyard areas under different climatic conditions, but it is more abundant in the Eastern and Northern parts of
Europe rather than in the South and the Mediterranean vineyards (Boudon-Padieu 2000b). Furthermore, the synchronization between phytoplasma and insect occurrence may be influenced by climatic factors. Along the latitudinal European gradient of grapes, climatic factors are thus good candidates to explain the vector geographical distribution. One hypothesis is that $S$. titanus is well adapted to cold winters and requires sufficient cooling to initiate diapause termination with consequences on synchrony between egg hatching and host plant and therefore reproductive success. A field survey in Corsica (warm winter) documented important overlapping between the different $S$. titanus larval instars, where young larvae and adults may occur simultaneously (Doncarli 1990). This may illustrate the link between cold winters and peaked egg hatching dynamics, while warm winters provoke the spreading of the hatchings over time.

Here, we test whether the diapause termination of a natural population of eggs depends upon the exposure to cold temperatures in winter in two experiments: (1) Eggs were subjected to different climatic conditions in order to reproduce winter conditions of two different French vineyards, Burgundy and Bordeaux; and (2) eggs were exposed to different cold time exposure. In this study, we used the cold definition by Salt (1961) where cold encompasses temperatures too low to support normal development of the insect. For $S$. titanus, we considered temperatures equal to or lower than $5{ }^{\circ} \mathrm{C}$ as cold. Because the eggs are inserted into the bark, they are supposed to be poorly exposed to light. Therefore, photoperiod influence or interaction with thermal factors has been neglected in this study.
Fig. 1 European vineyards with S. titanus occurrence. Arrows represent directions and importance of expansion of the insect since its first discovery in Southern France. Asterisks Occurrence reported in Croatia by Gabrijel in 1987

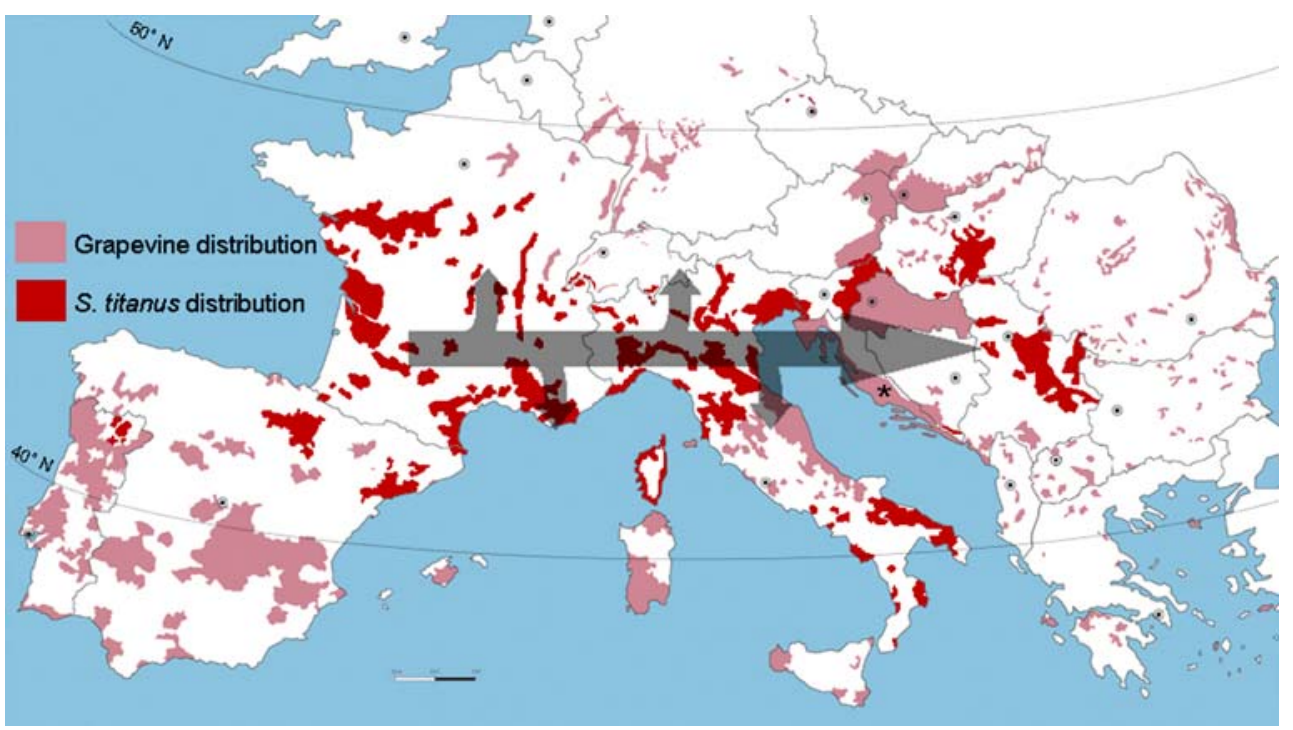




\section{Materials and methods}

\section{Insects}

Laying females insert their eggs deeply into the bark, which complicates egg counting because dissecting the bark often leads to egg destruction. Therefore, no reliable method could be used to count the numbers of living eggs on the woody canes. S. titanus egg populations were collected as described in Caudwell et al. (1970). Two-year-old grapevine woody canes were collected in an organic vineyard $60 \mathrm{~km}$ east of Bordeaux (Castillon-la-Bataille) where important populations of $S$. titanus were observed for successive years and during the preceding summer. Canes were extensively collected after pruning during the winter. The occurrence of eggs was checked by removing the bark of sample of 20 canes selected at random under microscope. Egg hatchings were obtained by placing wood pieces $(20-25 \mathrm{~cm}$ long) inside plastic hatching cages $(50 \times 38 \times$ $36 \mathrm{~cm})$ in a climatic chamber under a 16:8 (L/D) photoperiod, at $23 \pm 1{ }^{\circ} \mathrm{C}$, and $65-70 \% \mathrm{RH}$. To avoid egg desiccation, a $1-\mathrm{cm}$ layer of vermiculite (Efisol, France) was placed below the eggs and was humidified with distilled water every 7 days. In order to harvest neonate larvae, six cutting leaves of Cabernet-Sauvignon cultivar, maintained in a glass tube with water, were added to the cage ca. 20 days after eggs were removed from the cold room. Leaves were replaced when they began to wither.

In each hatchery cage, larvae were gently removed each day from the lower side of leaves with a mouth aspirator and the number of larvae hatched, and this was computed as hatching eggs. Observation ended when no more hatching occurred during 1 week.

\section{Cold temperature durations}

In this study, we set a temperature threshold of $5{ }^{\circ} \mathrm{C}$ and tested the effect of time spent at this temperature on the hatching dynamics of the eggs. Wood canes were kept at $5{ }^{\circ} \mathrm{C}$ before hatching for varying durations $(0,20,28,36$, 49 , and 63 days) in the conditions as described above. The canes were collected during the first week January 2006 and 2007.

Repeatability between replicates was gained by pooling batches of ca. $14 \mathrm{~kg}$ of canes, which were then shared randomly in eight samples of $1.6-1.7 \mathrm{~kg}$ each. Using this method, batches are expected to bear equivalent amounts of eggs. We recorded the day of the first hatching, the total number of hatchings per day, the median, and the total duration of hatching for each batch of grapevine woody canes.
Winter simulation

In order to avoid the effects of climatic conditions imposed upon eggs before cane collection, we used two environmental finely regulated climatic chambers (PR-25T, ESPEC) to simulate different winter conditions. We simulated the daily mean temperature recorded during the 2000-2001 winter in the Burgundy (Beaune) and Bordeaux areas (Castillon-laBataille) each under a constant short day photoperiod $8 \mathrm{~L}: 16 \mathrm{D}$. The former conditions were typical of a 93-day cold winter (298.2 degree-day) and the latter of a mild winter (821.4 degree-day; Fig. 2). Two-year-old grapevine canes bearing eggs were collected on mid-November, and $12 \mathrm{~kg}$ of canes was split into six hatching cages as described above. Three of them were exposed to a cold winter and the other three to a mild winter. After 3-month simulations, hatching cages were placed in climatic chamber as described above.

\section{Statistical analysis}

The effect of cold temperature was analyzed using the Spearman correlation test. Hatching dynamics were compared with the Kaplan-Meier survival method, and pair comparisons were performed with the log rank and Gehan-Wilcoxon tests. The log-rank test accounts for all events throughout the period of observation, while the Gehan-Wilcoxon test puts more weight onto early events (Pyke and Thompson 1986). The former allows a general study of the dynamics, whereas the latter test is better to compare precocity of hatchings. Profiles of the hatching dynamics were compared with the Spearman correlation test. All statistical analyses were performed using Statistica 6.0 (Stat Soft).

\section{Results}

Hatching dynamics

The egg cohort exposed to "Burgundy" winter hatched in a shorter period of time compared to those exposed to the

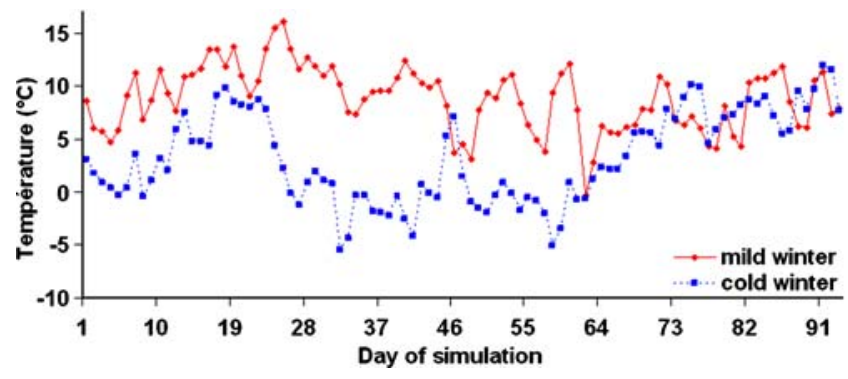

Fig. 2 Temperature program of simulated Burgundy (cold) and Bordeaux (mild) winters 
"Bordeaux" temperature conditions (log rank: $\chi^{2}=140$; Gehan-Wilcoxon: $\chi^{2}=304$; both: $P<0.001$; Fig. 3a). Hatchings of $25 \%, 50 \%$, and $75 \%$ of were reached, respectively, at 8,17 , and 25 days in cold winter conditions, whereas in mild winter, it took 17, 22, and 27 days. The hatching percentage peak was reached 6 days after hatching commenced for the eggs exposed to cold winter, while this peak was reached 20 days later for eggs exposed to mild winter. Despite the differences between the two KaplanMeier curves, the daily hatching variations over time were significantly correlated $\left(N=50 ; r_{\mathrm{S}}=0.44 ; P=0.001\right.$; Fig. 3a). The proportion of increase or decrease in number of hatchings evolved in the same way for the two conditions. The difference between the two hatching dynamics was mainly due to the difference in peak timing and affected $70 \%$ of the egg population. After the hatching peak of mild winter at 26 days, the dynamics were similar.

\section{a}

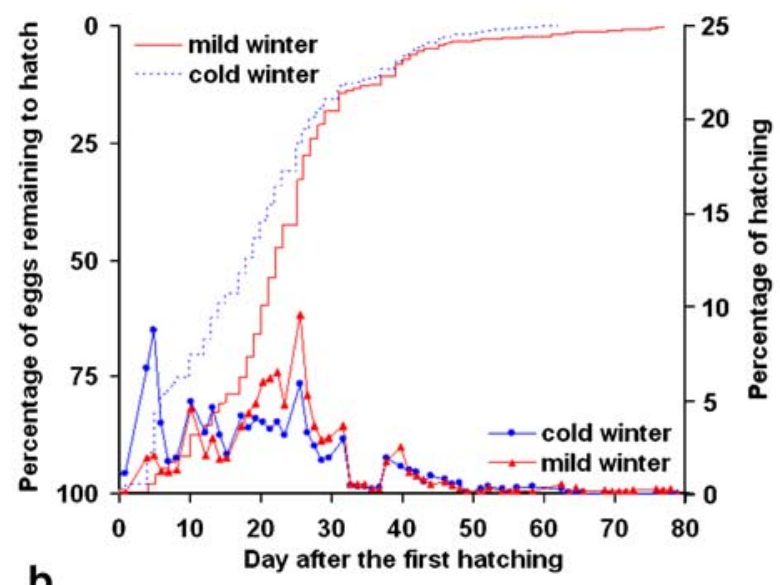

b

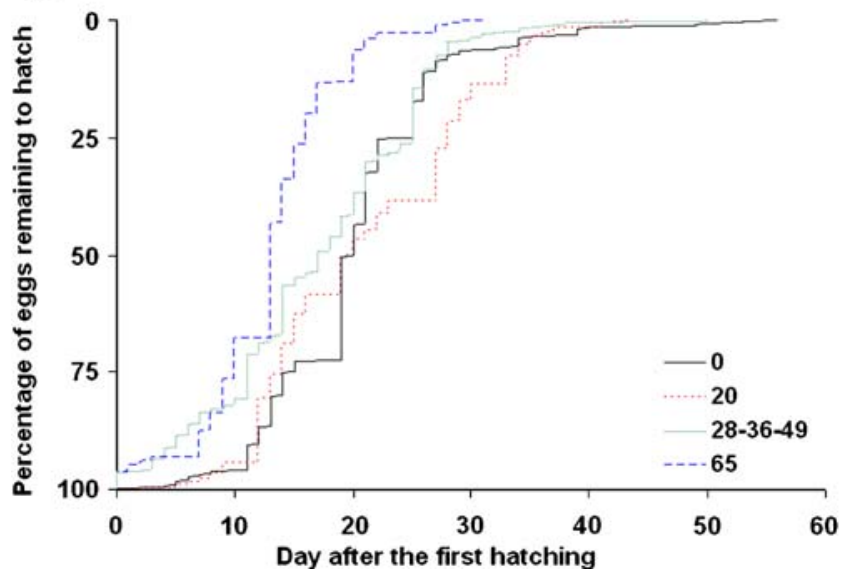

Fig. 3 a Cumulative percentage of hatching (Kaplan-Meier; non marked lines) and dynamics of hatchings in percentage of the overall (marked lines) of egg populations subjected to a Burgundy (cold) or a Bordeaux (mild) winter. b Cumulative percentage of hatching (Kaplan-Meier) from egg populations subjected to different $5{ }^{\circ} \mathrm{C}$ durations: $0,20,28,36,49$, and 65 days. The no statistical different curves $(28,36$, and 49 days) were pooled into a single curve
The $5{ }^{\circ} \mathrm{C}$ duration exposure clearly affected hatching dynamics $\left(N=6 ; \chi^{2}=834.98 ; P<0.001\right.$; Fig. 3b). Four statistical different classes of dynamics were obtained from the six treatments tested: class 0 day, class 20 days, class 28-36-49 days, and the class 63 days (Table 1).

First day and hatching length

The onset of hatching was negatively correlated to the cold time exposure $\left(N=8 ; r_{\mathrm{S}}=-0.97 ; P<0.001\right)$, as the time for $50 \%$ of hatching $\left(N=8 ; r_{\mathrm{S}}=-0.87 ; P<0.001\right)$. The number of days elapsed before the first hatching decreased with the exposure duration at $5{ }^{\circ} \mathrm{C}$, with a minimum for 80 days at $5^{\circ} \mathrm{C}$. Furthermore, the earlier hatching started, the faster the $50 \%$ of hatching was reached $\left(N=8 ; r_{\mathrm{S}}=0.82 ; P<0.001\right)$. There was no significant difference between hatching lengths whatever the cold time exposure $\left(N=8 ; r_{\mathrm{S}}=0.12\right.$; $P=0.286)$. Thus, for all the conditions, the longer the eggs were exposed to $5^{\circ} \mathrm{C}$, the quicker the first $50 \%$ hatchings occurred (Fig. 3b). The last half of hatching was (1) later than the control (no exposure at $5^{\circ} \mathrm{C}$ ) for 20 days at $5^{\circ} \mathrm{C},(2)$ the same for 28-36-49 days, and (3) earlier for 63 days. So, a short exposure to $5^{\circ} \mathrm{C}$ was necessary to obtain differences in the beginning of hatching dynamics when a long time was necessary to affect the end of hatchings.

\section{Discussion}

This work demonstrates that winter temperatures modify egg hatching in S. titanus. In countries where summer conditions are adequate for the complete achievement of the life cycle, warm winters (e.g., in Greece or southern Spain) may prevent the extension of the Flavescence dorée disease possibly by an asynchrony between diapause break and grape bud bursting. The time spent by the eggs at cold temperature (i.e., $\leq 5^{\circ} \mathrm{C}$ ) was negatively correlated to the time needed by an egg population to initiate hatching and to reach $50 \%$ of hatchings. Although chilling enhanced precocity and synchrony of hatchings, cold temperature did not induce a significant reduction of hatchings duration.

Diapause is a dynamic state during which the physiological conditions (diapause depth and intensity) change and for which photoperiod and temperature constitute the major diapause-maintaining environmental factors (Tauber and Tauber 1976). Low temperature, especially during the end of diapause, may help to prevent the exhaustion of metabolic reserves before diapause ends. Except for some species, chilling hastens insect diapause termination. This is the case for the burnet moth Zygaena trifolii (Lepidoptera: Zygaenidae) in which the shorter time to hatch results from longer chilling periods (Wipking 1995). Equally, the percentage of early-emerging Delia radicum (Diptera: 
Table 1 Hatching dynamics of the egg populations subjected to different $5{ }^{\circ} \mathrm{C}$ durations

\begin{tabular}{|c|c|c|c|c|c|c|c|}
\hline & & & \multicolumn{5}{|c|}{ Days at $5^{\circ} \mathrm{C}$} \\
\hline & & & 20 & 28 & 36 & 49 & 63 \\
\hline \multirow[t]{4}{*}{0} & Log rank & $\chi^{2}$ & 3.45 & 2.61 & 4.36 & 2.08 & 20.90 \\
\hline & & $P$ & $<0.001$ & $<0.01$ & $<0.001$ & 0.04 & $<0.001$ \\
\hline & Gehan-Wilcoxon & $\chi^{2}$ & 2.14 & 4.36 & 5.38 & 3.08 & 18.35 \\
\hline & & $P$ & 0.03 & $<0.001$ & $<0.001$ & $<0.01$ & $<0.001$ \\
\hline \multirow[t]{4}{*}{20} & Log rank & $\chi^{2}$ & & 4.19 & 11.76 & 4.14 & 27.59 \\
\hline & & $P$ & & $<0.001$ & $<0.001$ & $<0.001$ & $<0.001$ \\
\hline & Gehan-Wilcoxon & $\chi^{2}$ & & 5.53 & 10.79 & 4.04 & 26.14 \\
\hline & & $P$ & & $<0.001$ & $<0.001$ & $<0.001$ & $<0.001$ \\
\hline \multirow[t]{4}{*}{28} & Log rank & $\chi^{2}$ & & & 1.73 & 0.16 & 13.76 \\
\hline & & $P$ & & & 0.84 & 0.87 & $<0.001$ \\
\hline & Gehan-Wilcoxon & $\chi^{2}$ & & & 0.79 & 0.38 & 10.32 \\
\hline & & $P$ & & & 0.43 & 0.70 & $<0.001$ \\
\hline \multirow[t]{4}{*}{36} & Log rank & $\chi^{2}$ & & & & 2.18 & 14.18 \\
\hline & & $P$ & & & & 0.03 & $<0.001$ \\
\hline & Gehan-Wilcoxon & $\chi^{2}$ & & & & 0.86 & 9.81 \\
\hline & & $P$ & & & & 0.39 & $<0.001$ \\
\hline \multirow[t]{4}{*}{49} & Log rank & $\chi^{2}$ & & & & & 11.40 \\
\hline & & $P$ & & & & & $<0.001$ \\
\hline & Gehan-Wilcoxon & $\chi^{2}$ & & & & & 6.85 \\
\hline & & $P$ & & & & & $<0.001$ \\
\hline
\end{tabular}

Anthomyidae) from diapausing pupae is correlated with the increasing low temperature durations (Collier and Finch 1983). Such variation in precocity or lateness of diapause termination may be explained by the cold length exposure as shown by our work. As in numerous winter-diapausing insects in temperate zones (Collier and Finch 1983; Wipking 1995; Bosch and Kemp 2004), the time for S. titanus to hatch after being exposed as an egg to warm temperature $\left(20^{\circ} \mathrm{C}\right)$ decreases with cold duration during diapause.

But, differences in the earliest and latest emergence before diapause do not solely depend on environmental factors. Biron et al. (1998) have demonstrated in D. radicum the presence of early and late phenotypes which induced an asymmetrical bimodal distribution of the post-diapausing emergence. We observed the same pattern of hatching dynamic for eggs exposed to cold or mild winter. The hatchings lengths were similar. Only the beginning and the peak of hatching were different. Either an intrinsic hatching dynamic or an egg-laying dynamic may have contributed to the outcome, but because ages of the egg collected are not accurately known, we cannot separate these two strategies. In the two cases, the length and daily variations of hatching appear to match a risk-spreading strategy. According to Hopper (1999), two population strategies may have occur in our work: (1) two genotypes of females coexist, one which lays eggs adapted to cold winter and another laying mild winter-adapted ones; (2) a single genotype of females produces phenotypes that lay eggs with different temperature hatching requirements. These two strategies would both be advantageous in unpredictable and varying winter conditions.

In phytophagous univoltine species, synchrony of the larvae with the targeting host organs reduces starvation periods and minimizes larval mortality. For optimal larval survival, S. titanus eggs should hatch during or closely following bud bursting of $V$. vinifera when young leaves present the highest nitrogen content (Mooney and Gulmon 1982), which in turn increases the fitness of other leafhoppers (Rossi and Strong 1991). Thus, individuals of Drepanosiphum platanoidis (Homoptera: Callaphididae) hatching while host-plant Acer pseudoplatanus (Sapindales: Aceraceae) bud bursting can double their adult weight, and their offspring can also grow up faster as compared to aphids that hatching after bud bursting (Dixon 1976). Moreover, their survival was negatively correlated with the time elapsed between egg hatch and bud bursting (Dixon 1976).

Like most temperate-zone deciduous fruit crops, grapes undergo bud dormancy, which is a phase of development that enables these plants to survive unfavorable winter conditions. Bud dormancy is genetically controlled, naturally induced by photoperiod and low temperatures, and released after exposure to adequate chilling temperatures. Vernalization is thus essential in many plants, for example to promote flowering (Henderson and Dean 2004) or bud burst. So, time required to initiate bud break, number of 
breaking buds per vine stock, and synchrony between first and last bud to break increase with the duration of chilling in grapevines (Kliewer and Soleimani 1972). Increasing temperature causes earlier budburst in $V$. vinifera (Duchêne and Schneider 2005), and we show here that it may delay egg hatching. Therefore, asynchrony between egg hatching and bud burst may be associated with higher temperatures in winter and has severe consequences in larval survival (Watt and McFarlane 1991). As a comparison, the modeling of climatic warming on synchrony of Operophtera brumata (Lepidoptera: Geometridae) and Picea sitchensis (Pinales: Pinaceae) in Scotland show a time-lag of $20 \pm 2.5$ days when subjected to a $2^{\circ} \mathrm{C}$ increase in ambient temperature (Dewar and Watt 1992). With future warmer winters (Parry et al. 2007), one should expect an increase in the time required for a batch of eggs to hatch with a peak delayed, while grapevine bud burst will be advanced. This could result in a desynchronization between the host and parasite. The majority of larvae will be expected to appear on older leaves that have poorer nutritional value (Mooney and Gulmon 1982). This may lead to a general fitness decline in $S$. titanus populations. These differences between cold winter vineyard conditions (i.e., good synchrony between hatching and plant phenology) and mild winter vineyard conditions (i.e., bad synchrony) were observed for 7 years in Burgundy and 5 years in Côte d'Azur vineyards (Sentenac unpublished data).

After an insect inoculation in a leaf, phytoplasmas move down to the roots and multiply (Boudon-Padieu 2000a). The next spring, phytoplasmas move up to developing shoots with an irregular distribution (Boudon-Padieu 2000a). It has been demonstrated that phytoplasma distribution gets more uniform over time (Wei et al. 2004). Therefore, the more the hatching peak is close to the bud break, the smaller the probability to meet a phytoplasma for a leafhopper is. Because of the period of latency (4 to 5 weeks) after phytoplasma acquisition before the insect becomes infective, the younger they acquire phytoplasmas, the longer they will be vectors. Males hatch before females, are more efficient at phytoplasma acquisition (Lefol et al. 1994; Beanland et al. 1999), and also move more than females (Hunt et al. 1993; Lucchi et al. 2004). Therefore, males are better vectors than females. So, even though the effect of temperature on phytoplasma multiplication in the plant has been poorly documented, the consequences of winter on hatching dynamic may greatly impact the Flavescence dorée spread. After a cold winter, grapevine bud break is delayed (Duchêne and Schneider 2005) and $S$. titanus hatchings are earlier. So, fewer young leafhoppers (especially males which hatch the first) will be in contact with a high occurrence of phytoplasma in the plant, conversely after a mild winter when bud break occurs sooner and hatchings later.
The Flavescence dorée vector was introduced from North America to Europe in the 1950s, and the cold temperatures request for diapause control is consistent with its origin. Sufficient cooling thus regulates the diapause termination and the egg hatching. This may result in peaked egg hatching dynamics, while warm winters provoke the spreading of the hatchings over time as it may be observed in several French south east vineyards (Doncarli 1990). This requirement for cold is a likely explanation for the insect's limited spread into Southern Europe in comparison to its spread to the East and North. If short summers are a barrier to northern progression of this leafhopper because insects have difficulties to achieve their complete life cycle (Boudon-Padieu 2000a), climate change with longer and hotter summers should favor the spreading of $S$. titanus to northern vineyard as in Germany by extending the favorable developing season (Boudon-Padieu and Maixner 2007). However, winter warming, in the Southern limit of their current distribution, may eventually lead to a decrease in insect density or extinction in certain areas such as Basilicate (South of Italy) where populations are small (Viggiani 2002).

This work is a first step toward understanding the population dynamics of $S$. titanus and how it synchronizes with its host-plants, $V$. vinifera. Here, we limited our focus on the responses of the eggs to cold temperature exposure and particularly on the effects of this upon spring hatching. Our results may lead to a better understanding of the distribution spread of this invasive species and its population dynamics under different vineyard areas.

Acknowledgments Mrs. E. Dion (UMR BIO3P, Univ. Rennes) is acknowledged for her experimental contribution, G. Sentenac (Institut Français du Vin, Beaune) for providing us personal unpublished observations, Dr. J. Moreau (UMR Biogéosciences, Univ. Dijon) for his contribution in statistics, P. Cartolaro (our lab) for his help in carefully surveying the microclimatic chambers functioning, and Dr. S. Ahmed (Univ. Reading) for help with the English check of our manuscript. This project and first author were supported by a Ph.D. grant from the Conseil Interprofessionnel des Vins de Bordeaux, the region Aquitaine, and the scientific Dept. INRA SPE.

Conflict of interest The authors declare that they have no conflict of interest and certified that the experiments comply with the French current laws.

Open Access This article is distributed under the terms of the Creative Commons Attribution Noncommercial License which permits any noncommercial use, distribution, and reproduction in any medium, provided the original author(s) and source are credited.

\section{References}

Beanland L, Hoy CW, Miller SA, Nault LR (1999) Leafhopper transmission of the aster yellows phytoplasma: Does sex matter? Environ Entomol 28:1101-1106 
Bertin S, Guglielmino CR, Karam N, Gomulski LM, Malacrida AR, Gasperi G (2007) Diffusion of the Neartic leafhopper Scaphoideus titanus Ball in Europe: a consequence of human trading activity. Genetica 131:275-285

Biron D, Langlet X, Boivin G, Brunel E (1998) Expression of early and late-emerging phenotypes in both diapausing and non-diapausing Delia radicum L. pupae. Entomol Exp Appl 387:119-124

Bonfils J, Schvester D (1960) Les cicadelles (Homoptera Auchenorhyncha) dans leurs rapports avec la vigne dans le Sud-Ouest de la France. Ann Epiphyties 3:325-336

Bosch J, Kemp WP (2004) Effect of pre-wintering temperature regimes on weight loss, survival, and emergence time in the mason bee Osmia cornuta (Hymenoptera: Megachilidae). Apidologie 35:469-479

Bosco D, Alma A, Arzone A (1997) Studies on population dynamics and spatial distribution of Scaphoideus titanus leafhoppers in vineyards (Homoptera: Cicadellidae). Ann Appl Biol 130:1-11

Boudon-Padieu E (2000a) Cicadelle vectrive de la Flavescence dorée Scaphoideus titanus Ball, 1932. In: Stoeckel J (ed) Ravageurs de la Vigne, 1st edn. Féret, Bordeaux, pp 110-120

Boudon-Padieu E (2000b) Grapevine phytoplasmas. In: First internet conference on phytopathogenic mollicutes. The Phytoplasma Working Group. http://www.uniud.it/phytoplasma/pap/boud8290. html. Accessed 3 Sep 2008

Boudon-Padieu E, Maixner M (2007) Potential effects of climate change on distribution and activity of insect vectors of grapevine pathogens. Colloque international et pluridisciplinaire sous l'égide de la chaire UNESCO Vin et Culture, Dijon, p 23

Bressan A, Spiazzi S, Girolami V, Boudon-Padieu E (2005a) Acquisition efficiency of Flavescence dorée phytoplasma by Scaphoideus titanus Ball from infected tolerant or susceptible grapevine cultivars or experimental host plants. Vitis 44:143-146

Bressan A, Girolami V, Boudon-Padieu E (2005b) Reduced fitness of the leafhopper vector Scaphoideus titanus exposed to Flavescence dorée phytoplasma. Entomol Exp Appl 115:283-290

Bressan A, Larrue J, Boudon-Padieu E (2006) Patterns of phytoplasma-infected and infective leafhoppers in vine yards with high incidence of Flavescence doréée. Entomol Exp Appl 119:61-69

Caudwell A, Kuszala C, Bachelier JC, Larrue J (1970) Transmission de la Flavescence dorée de la vigne aux plantes herbacées par l'allongement du temps d'utilisation de la cicadelle Scaphoideus littoralis Ball et l'étude de sa survie sur un grand nombre d'espèces végétales. Ann Phytopathol 2:415-428

Collier RH, Finch S (1983) Effects of intensity and duration of low temperature in regulating diapause development of the cabbage root fly (Delia radicum). Entomol Exp Appl 34:193-200

Denlinger DL (2002) Regulation of diapause. Ann Rev Entomol 47:93-122

Dewar RC, Watt AD (1992) Predicted changes in the synchrony of larval emergence and budburst under climatic warming. Oecologia 89:557-559

Dixon AFG (1976) Timing of egg hatch and viability of the sycamore aphid, Drepanosiphum platanoidis (Schr.), at bud burst of sycamore, Acer pseudoplatanus L. J Anim Ecol 45:593-03

Doncarli M (1990) Contribution a la connaissance de la biologie et de l'éthologie de Scaphoideus titanus cicadelle de la Flavescence dorée. Mémoire de DESS, Université de Corse Pasquale Paoli, p 35p

Duchêne E, Schneider C (2005) Grapevine and climatic changes: a glance at the situation in Alsace. Agron Sustain Dev 25:93-99

Ellers J, van Alphen JJM (2002) A trade-off between diapause duration and fitness in female parasitoids. Ecol Entomol 27:279-284

Gibson LP (1973) An annotated list of the Cicadellidae and Fulgoridae of elm. Res. Pap. NE-278. Upper Darby, PA: U.S. Department of Agriculture, Forest Service, Northeastern Forest Experiment Station. 5 p.
Henderson IR, Dean C (2004) Control of Arabidopsis flowering: the chill before the bloom. Development 131:3829-3838

Higaki M, Ando Y (2002) The effect of temperature on embryonic development and local adaptation in the life cycle of Eobiana engelhardti subtropica Bey-Bienko (Orthoptera: Tettigoniidae). Appl Entomol Zool 37:625-636

Hopper KR (1999) Risk-spreading and bet-hedging in insect population biology. Ann Rev Entomol 44:535-560

Hunt RE, Parr JC, Haynes KF (1993) Influence of leafhopper (Homoptera: Cicadellidae) gender and female mating status on plant disease dynamics within a simple habitat. Environ Entomol 22:109-115

Kliewer WM, Soleimani A (1972) Effect of Chilling on Budbreak in 'Thompson Seedless' and 'Carignane' Grapevines. Am J Enol Vitic 23:31-34

Kroon A, Veenendaal RL (1998) Trade-off between diapause and other life-history traits in the spider mite Tetranychus urticae. Ecol Entomol 23:298-304

Lefol C, Lherminier J, Boudon-Padieu E, Larrue J, Louis C, Caudwell A (1994) Propagation of Flavescence dorée MLO (mycoplasmalike organism) in the leafhopper vector Euscelidius variegatus Kbm. J Invertebr Pathol 63:285-293

Lessio F, Alma A (2006) Spatial distribution of nymphs of Scaphoideus titanus (Homoptera: Cicadellidae) in grapes, and evaluation of sequential sampling plans. J Econ Entomol 99:578-582

Lucchi A, Mazzoni V, Presern J, Virant-Doberlet M (2004) Mating behaviour of Scaphoideus titanus Ball (Hemiptera: Cicadellidae). 3rd European Hemiptera Congress, Saint Petersburg, Russia, 811 June

Menu F, Desouhant E (2002) Bet-hedging for variability in life cycle duration: bigger and later-emerging chestnut weevils have increased probability of a prolonged diapause. Oecologia 132:167-174

Meyerson LA, Mooney HA (2007) Invasive alien species in an era of globalization. Front Ecol Environ 5:199-208

Mooney HA, Gulmon SL (1982) Constraints on leaf structure and function in reference to herbivory. BioScience 32:198-206

Papura D, Giresse X, Caron H, Van Helden M (2006) Ten polymorphic microsatellite markers for Scaphoideus titanus, the vector of flavescence dorée phytoplasma. Mol Ecol Notes 6:1114-1116

Papura D, Van Helden M, Giresse X, Salar P, Danet JL, Foissac X, Malembic-Maher S (2007) Genetic structure of Scaphoideus titanus populations and genetic diversity of the epidemic strains of "flavescence doree" phytoplasma: the situation in France. Bull Insectology 60:333-334

Parry ML, Canziani OF, Palutikof JP (2007) Technical summary. In: Parry ML, Canziani OF, Palutikof JP, van der Linden PJ, Hanson CE (eds) Climate change 2007: impacts, adaptation and vulnerability. Contribution of Working Group II to the Fourth Assessment Report of the Intergovernmental Panel on Climate Change. Cambridge University Press, Cambridge, pp. 23-78

Pimentel D, Zuniga R, Morrison D (2005) Update on the environmental and economic costs associated with alien-invasive species in the United States. Ecol Econ 52:273-288

Pyke DA, Thompson JN (1986) Statistical analysis of survival and removal rate experiments. Ecology 67:240-245

Rossi AM, Strong DR (1991) Effects of host-plant nitrogen on the preference and performance of laboratory populations of Carneocephala floridana (Homoptera: Cicadellidae). Environ Entomol 20:1349-1355

Salt RW (1961) Principles of Insect Cold-Hardiness. Ann Rev Entomol 6:55-74

Tauber MJ, Tauber CA (1976) Insect seasonality: diapause maintenance, termination, and postdiapause development. Ann Rev Entomol 21:81-107

Van Asch M, Visser ME (2007) Phenology of forest caterpillars and their host trees: the importance of synchrony. Ann Rev Entomol 52:37-55 
Vidano C (1966) Scoperta della ecologia ampelofila del Cicadellide Scaphoideus littoralis Ball nella regione neartica originaria. Ann Fac Sci Agrar Univ Studi Torino III:297-302

Viggiani G (2002) Il vettore della flavenza dorata trovato in Basilicata. Inf Agrar 58:59

Wang XP, Xue FS, Hua A, Ge F (2006) Effects of diapause duration on future reproduction in the cabbage beetle, Colaphellus bowringi: positive or negative? Physiol Entomol 31:190-196

Watt AD, McFarlane AM (1991) Winter moth on Sitka spruce: synchrony of egg hatch and budburst, and its effect on larval survival. Ecol Entomol 16:387-390
Wei W, Kakizawa S, Suzuki S, Jung HY, Nishigawa H, Miyata S, Oshima K, Ugaki M, Hibi T, Namba S (2004) In planta dynamic analysis of onion yellows phytoplasma using localized inoculation by insect transmission. Phytopath 94:244250

Wipking W (1995) Influences of daylength and temperature on the period of diapause and its ending process in dormant larvae of burnet moths (Lepidoptera, Zygaenidae). Oecologia 102: 202-210

Yukawa J (2000) Synchronization of gallers with host plant phenology. Popul Ecol 42:105-113 